\title{
The Role Played By NGOs in Augmenting Government Efforts towards the Achievement of Millennium Development Goal of Combating HIV and AIDS in Zimbabwe
}

\author{
Zungura Mervis \\ Lecturer: Department of Political and Administrative Studies \\ University of Zimbabwe \\ Email: zunguramervis@gmail.com
}

Received:November 19, 2012 Accepted:December 16, 2012 DOI:10.5296/jpag.v2i4.2732

\begin{abstract}
This article examines the role of NGOs in complementing government efforts towards the achievement of millennium development goal of combating HIV and AIDS by 2015. Documentary research, key informant interviews, in-depth interviews and focus group discussions were used to investigate the extent to which government and NGOs coordinate their functions to avoid duplication of functions in their areas of operation as well as examining the net effect of NGO involvement in HIV/AIDS programmes. Evidence from researches points to visible Government commitment to the eradication of the disease as evidenced by the formulation of the National Aids policy and the formation of the parliamentary portfolio committee on health. NGOs have also played a pivotal role in HIV and AIDS programmes by implementing government policies both in urban and rural areas of Zimbabwe. Notwithstanding this, lack of coordination of functions between NGOs and government has derailed the national response as studies highlight concentration of HIV/AIDS programmes in some areas whilst other areas have no programmes at all. Government's requirement that NGOs must submit their work plans has not been adhered to by NGOs leading to mutual suspicion between the two. NGOs should comply with government demands to avoid cancellation of their contracts and the government must create a conducive working environment for NGOs for the attainment of MDG six.
\end{abstract}

Keywords: MDGs, HIV/AIDS, NGOs, Beam 


\section{Introduction}

In 2000 world leaders set up eight Millennium Development Goals (MDGs) to be attained by 2015.The MDGs are to: (1) eradicate poverty and hunger; (2) achieve universal primary education; (3) promote gender equality and empower women; (4) reduce child mortality; (5) Improve Maternal Health; (6) combat HIV and AIDS, Malaria and other diseases; (7) ensure environmental sustainability and; (8) develop a global partnership for development (Millennium Development Report). Zimbabwe was among the 189 heads of states and government which agreed to the Millennium Declaration at the Millennium Summit of September 2000. The government of Zimbabwe branded goals number 1, 3 and 6 as the national priorities. According to the MDGs Status Report Zimbabwe (2010, viii) prioritisation of goals 1, 3 and 6 is based on the fact that non-attainment of these goals would undermine the achievement of all other goals. Goal number 6 is concerned with combating HIV and AIDS, malaria and other diseases. The thrust of this article is the role played by NGOs in augmenting government efforts towards reducing HIV prevalence from 13.6 percent to nine percent by 2015 .

The southerntimesafrica.com of 22 August 2010 argues that Zimbabwe continues to get little support from the Global Fund due to political and economic crisis that characterised the country over the ten years. Despite this lack of financial capacity, Zimbabwe is likely to attain the MDG target of nine percent by 2015(MDG Status Report 2010.34).This is a result of the combined efforts of government and NGOs. The government of Zimbabwe formulates policies on HIV and AIDS which are implemented by NGOs. To analyse the contributions made by both parties towards the attainment of goal 6, government and non-governmental HIV and AIDS programmes will be examined. To this end, the following questions guided the study:

- What measures have been adopted by government in combating HIV and AIDS?

- How are NGOs augmenting government efforts in combating HIV and AIDS?

- What major constraints are faced by both government and NGOs in implementing HIV/AIDS programmes?

- How is the nature of funding affecting efforts towards combating HIV and AIDS?

\section{Background to the problem}

According to www.undp.org globally there are 34 million people living with HIV and AIDS in the world. The United Nations General Assembly Special Session on HIV/AIDS (UNGASS) 2001 chronicles with grave concern that Africa, in particular Sub-Saharan Africa, is currently the worst affected region, where HIV/AIDS threatens development, social cohesion, political stability, food security and life expectancy (The Human Development Report, (2003, 2). According to the United Nations General Assembly Special Session Report on HIV and AIDS (UNGASS (2008-2009, annex 1), of all the people living with HIV and AIDS, 22.0 million people live in sub- Saharan Africa. Zimbabwe is one of the countries in sub-Saharan Africa that has been worst affected by the HIV and AIDS epidemic. The HDR(ibid) claims that HIV already found fertile socio-economic grounds which presented an ideal environment 
for its rapid spreading in 1985 when it first struck Zimbabwe. Even though HIV prevalence reached alarming levels in the early 1990s, www.un.org notes that the global response to AIDS has demonstrated tangible progress towards the achievement of MDG 6. Globally, the number of new infections fell steadily from a peak of 3.5 million in 1996 to 2.7 million in 2005. Deaths from AIDS related illnesses dropped from 2.2 million in 2004 to 2 million in 2005. Identical to the global response, Zimbabwe's response to AIDS has been positive. The Zimbabwe National HIV and AIDS Strategic Plan (ZNASP) 2011-2015 observes that Zimbabwe had exceptionally high levels of HIV prevalence in the past and significantly lower levels at present. Decline in HIV prevalence in Zimbabwe is projected to have started in the late 1990s. In cognisance of the role played by NGOs, www.aidsalliance.org notes that this decline is attributed to NGOs and civil society as the country has been hit by political and economic crisis. National AIDS Council (NAC) enacted through the 1999 Act of Parliament to coordinate and facilitate the national multi-sectoral response to HIV/AIDS according to nac.org. $z w$, is experiencing challenges in performing its purposes. Even though the act gives NAC the power to implement programmes it is generally agreed that its role is to lead and coordinate the national response.

According to the MDGs Report (2004, i) goal number 6 comprises of quantitative/measurable goals, time targets and numerical indicators. Combating HIV and AIDS has two targets which are $6 \mathrm{a}$ and $6 \mathrm{~b}$. Target $6 \mathrm{a}$ is to halt and begin to reverse the spread of HIV/AIDS. Indicators for target 6a are three which are (a) HIV prevalence among males and females aged 15-24 (b) condom use as at high-risk sex (c) proportion of population aged 15-24 with comprehensive knowledge of HIV and AIDS

Documentary evidence shows that Zimbabwe has shown a marked development towards the reduction of HIV prevalence among males and females aged 15-24. HIV first struck Zimbabwe in 1995, by 2002, 2.3 million people had been infected and the adult prevalence rate was 34\% (UNAIDS Report 2005).Zimbabwe was experiencing one of the world's most severe HIV and AIDS epidemics and was the second highest in prevalence after Botswana at 36\% in 2002 (Ministry of Health and Child Welfare, 2008). Data from ante-natal clinic and surveillance surveys indicate that HIV prevalence in Zimbabwe increased from 29\% in 1997 to $34 \%$ in 2000 (ibid). AIDS prevalence however started to decline after 2000 with the 2001 ante-natal information revealing a prevalence rate of $30.4 \%$ among pregnant women (ibid).Infection rates among women aged between 20-39 years were very high. According to the sameantenatal survey of 2000, the prevalence rate among the 15-24 age groups was $32 \%$. Other age groups' HIV prevalence rates were as follows: age group 20-24 years at $28.9 \%$, 25-29 years at 36.5\%,30-34 years at 39.9\%, and 35-39 years at 31\%.According to the MDG Status Report (2010, 32) Zimbabwe has continued to register a gradual decline in HIV prevalence as demonstrated by the trend in prevalence rates over the past decade. In 2001, the estimated HIV prevalence in adults aged 15 to 49 years was 23.7 but it dropped to $18.1 \%$ in 2005/2006 (UNGASS 2008-2009). The national HIV estimates of 2009 revealed a further decline in prevalence rate to $14.3 \%$. The country's prevalence rate is now 13.7 , though Minister Mombeshora still laments that it's still too high as the country gets closer to the MDG and ZNASP target of a single digit (english.people.com.cn).The MDG Status Report 
(2010, 32), argues that condom use by men aged $15-24$ was $68 \%$ and $42 \%$ for women of the same age.

Target $6 \mathrm{~b}$ was to achieve by 2010 , universal access to treatment for HIV and AIDS for all those who need it. The heads of states and government agreed on one indicator for target $6 \mathrm{~b}$ which is the proportion of people aged 15-24 with advanced HIV infection with access to anti-retroviral drugs. Although Zimbabwe is being hailed by the United Nations for having some of the best HIV and AIDS intervention programmes in the world, the country continues to get very little in terms of donor support from the Global Fund (southern timesafrica.com). Combined with the negative impacts of droughts and floods and the international isolation, difficulties have been encountered in trying to achieve by 2010, universal access to treatment for HIV and AIDS for all those who needed it. In 2002 the government declared the treatment shortage as a national emergence thus allowing Zimbabwe to produce and purchase Aids drugs locally under international law, thereby reducing their costs. However in October 2005 it was reported that the cost of antiretroviral drugs had quadrupled in three months (Aids Map $5^{\text {th }}$ October 2005). Increases in the cost of the drug led to the flooding of fake drugs on flea markets. According to AllAfrica.com as the income of households tends to be low, rural women who often rely upon their husbands working in urban areas for financial support, cannot afford the cost of drugs. Prices of ARVs have hindered their accessibility especially to villagers in rural Zimbabwe during the 2005 period. This problem was further aggravated by brain drain.

The Ministry of Health and Child Welfare (MOHCW) introduced the OI/ART programme in April 2004 and Plan for the Nationwide Provision of ART was finalised in December 2004 covering the period 2005-2007 (MOHCW 2005-2007). ART coverage increased from about 5000 to $100000(29 \%)$ by December 2007. The (UNGASS 2009, 18) reports that the number of adults and children accessing ART were 148144 (39.7\%) in December 2008 and 215109 (56.8) in November 2009. Subsidies given by government to local manufacturers of ARVs through the provision of foreign currency for purchase of raw materials and waiver of duty on raw materials for local production and imported ARVs in 2008 aided in the improved supply of the drug in 2009. Minimum numbers of sites experienced drug stock outs.

\section{Literature Review}

\subsection{The participatory approach}

There is a shift to participatory approaches in the contemporary development discourse. Proponents of decentralised or community based approaches argue that development agencies should focus more on working with societies at community level to motivate behavioural change and support for those affected by HIV and AIDS,(Dejong (2003:16). Participatory approaches attach more importance on ensuring that individuals and communities have information and ultimately knowledge as well as power to reduce vulnerability in their communities. Participatory approaches allow NGOs to carry out situational analyses which enable them to understand the HIV situations in their areas. This according to World Vision $(W V)$ Toolkit $(2002,10)$ is a critical step in the development of any programme so that it addresses the needs of the respondents as perceived by the respondents (communities). $W V$ 
Toolkit (ibid) notes that even though a project is well defined if it does not address the needs as perceived by the community, that project does not work well.

Participatory approaches become more applicable to the role played by non-governmental organisations in communities. A case in point is the National Behaviour Change (BC) Strategy 2006 which is a comprehensive top-down approach whose main objective is reducing sexual transmission of HIV and AIDS. Focus of BC is to address the underlying factors of HIV and AIDS epidemic in Zimbabwe such as multiple concurrent partnerships, age difference sexual relationships and long- term discordant couples. The BC component according to the Request for Proposals (2011:29) is administered in 16 districts by Expanded Support Programme and a further 10 districts with the European Community support which are not governmental institutions. NAC which is for the top-down approach only coordinates the $\mathrm{BC}$ programme and implementation at district levels is done by eight NGOs contracted by UNFPA. NGOs as Dejong (2003: 10) summaries are more immediately concerned about changing the underlying social parameters in which HIV and AIDS are carried out. Rendering to www.worldvision.org, WV's strategic presence at the community permits it to improve access as well as creating demand for PMTC services. WV is positioning itself to improving assistance to communities by bringing community and home based care to people living with HIV and AIDS (PLWHA) complementing government and other partners' leading to the combating of HIV and AIDS.

\subsection{Conceptual Framework}

\subsection{The Policy Framework}

The policy process is divided into four phases, namely, the agenda setting, policy formulation, implementation and evaluation(Walt, 1994, 40). Policy development starts with problem definition. During this stage, a problem is identified and examined, and possible solutions are explored through research and analysis. The second stage in policy development is agenda setting. Awareness is raised both at community and at decision making levels. The third stage of policy formation is when policies are enacted by government as public policies. The government has been formulating different HIV/AIDS policies since 1999. Among the policies is the National AIDS policy administered by NAC. Government has shown its political commitment to the eradication of the disease. The next stage is implementation in which both state and non-state players are involved. Implementation is a very critical stage as decisions are made which determine the effectiveness of a policy. Values and ideas of NGOs affect the policy making process as NGOs are also implementing agencies. The last stage is policy evaluation. Policy evaluation measures the success of a policy. Thus evaluation of HIV/AIDS policies depends on the measures and decisions undertaken by NGO as well as the government on policy implementation. Implementation of policies by NGOs implies that public policies are therefore not public as decisions made by non-state actors have a bearing on policy reformulation. Policy reformulation therefore hinges on recommendations done by government and NGO actors. The study is therefore premised on a core issue in public administration which is on public private partnerships. HIV policies are therefore implemented in terms of the public private partnerships. 


\section{Research Findings}

\subsection{Political Commitment}

Documentary search shows that the government of Zimbabwe has continued to demonstrate commitment and leadership on the national response to HIV and AIDS (UNGASS Report 2009, 13). In 1985, after the first HIV and AIDS case in Zimbabwe was reported, the Ministry of Health through the National Blood Transfusion Services (NBTS) intensified the screening of donated blood and blood products. In 1987 the National AIDS Control Programme (NACP) was established in the Ministry of Health. A one-year Emergency Short-Term Plan (STP) was formulated to create public awareness of HIV and AIDS. According to the ZNASP 2004, health personnel were trained in the different aspects of HIV and AIDS interventions to include promotion of appropriate behaviour change among targeted population groups, counselling and caring for people living with HIV and AIDS, surveillance and monitoring the epidemic through epidemiological surveillance. The First Medium Term Plan (MTP1) was launched in 1989 and remained operational until 1994. The MTP1 focused on expanding interventions to promote behaviour change, prevention and treatment of Sexually Transmitted Disease (STD), care and support for PLWHA. In 1994, the five year Second Medium Term Plan (MTP2) was developed to focus on mobilization of non-health sectors to integrate HIV and AIDS issues. In 1999 the government formed the National AIDS Council (NAC) with a mandate to coordinate all HIV and AIDS prevention, support and care, mitigation and research efforts. Since its inception, the operations of the National AIDS Council have been guided by a series of policies which have been reviewed over the years in response to changing trends (nac.org.co.zw) To operationalize the National HIV/AIDS Policy, the Zimbabwe National HIV/AIDS Strategic Framework (ZNASP) (2000-2004) was developed and launched in 2000. From 2006-2010 Zimbabwe implemented the ZNASP 2006-10 which was replaced by ZNASP 2010-15.

\subsection{Policy Implementation Capacity}

Even though government had shown commitment to the Millennium Development Goal of combating HIV and AIDS by the formation of the HIV AIDS policy in 1999 and the formation of NAC to execute the policy, documentary sources and interviews show problems that are encountered during the implementation of the policy. According to www.nac.org, initially NAC disbursed funds to organisations working in HIV which only benefited established organisations who had the expertise in proposal writing. It was only in 2002 that funds started to be channelled through DAAC to the villages. Despite Zimbabwe's excellent HIV policies, the country lacks adequate professionals due to brain drain. This has greatly affected the execution of HIV/AIDS policies. The country experienced a severe shortage of healthcare workers which manifested in long waiting lists and administration problems. In-depth interviews with matrons at major hospitals have indicated that the country continues to lose doctors and experienced nurses to private organisations. Vacancies left with these professionals are not filled since the government has frozen jobs. To clear queues of patients collecting their monthly medication, nurse aids are assisting by attending to patients. This is a very sad scenario as it might lead to wrong medication of HIV/AIDS patients. Interviews 
with patients indicated that between 2007 and 2008 they failed to access drugs for some weeks which caused serious health problems to them. In-depth interviews reviewed that some HIV/AIDS patients even died in queues trying to access treatment at district hospitals during this period. Zimbabwe has good policies which are not supported by requisite resources. Political commitment has resulted in major radio and television programmes addressing issues related to HIV and AIDS.

\subsection{Parliamentary Controls}

The UNGASS Report $(2009,13)$ propounds that Zimbabwe has a very active multi-party parliamentary portfolio committee on Health which is executing the following functions:

- Budget oversight where the committee facilitates in resource mobilisation and advocates for allocation of more funds to NAC. The committee also tracks external funding to the Ministry of Health and Child Welfare through NGOs and other bilateral partners

- Review of current policy, strategic documents and legislature so that these are in line with the current situations. The committee has significant input in the ZNASP programmes and it is in the process of reviewing the NAC Act. Other legislation that the Portfolio Committee constantly monitors for inconsistencies with current situations include the Public Health Act, Domestic Violence Act, Sexual Offenses Act and Child Adoption Act and of which have relevance to HIV/AIDS

- Tracking the implementation of the policies and legislation through site visits to interview beneficiaries.

\subsection{Performance of NACs}

According to the $H R D(2008,130)$ NAC activities are currently wholly locally funded as only $3 \%$ of its budget comes from donors who prefer to fund NGO activities because of prevailing international relations impasse between Zimbabwe and segments of the international community. In-depth interviews with National Association of Nongovernmental Organisations officials pointed out to the mismanagement of the AIDS levy due to lack of experienced staff both at national government and at ward as well as village levels. This is supported by documentary evidence which shows that by 2002 only $30 \%$ of the AIDS levy has been disbursed, meaning that resources were lying idle while people were suffering (UNICEF 2003). Makumbe 1996, 443-7) argues that even though local government structures were already in existence, they have never been exposed to managing their own resources and implementing their own development plans. Misuse of AIDS funds was evidenced in several districts due to lack of expertise. NAC is alleged to be failing to track the implementation of its policies because of lack of adequate funding and its hierarchical structure.

\subsection{Access to Anti-Retroviral Therapy and Home based Care Programmes}

Governments have increasingly recognised the importance of providing access to treatment for those infected with HIV/AIDS (www.un.org.gvt). The MOHCW introduced OI/ART 
programme in April 2004 and by December 2007 ART coverage increased from 5000 to 100 000. According to the $\mathrm{MOHCW} 2009$ the number of adults accessing ART were $39.7 \%$ in December 2008 and 56.8\% in November 2009. In 2010300000 accessed ART out of a target of 340000 though this number increased with the World Health Organisation's recommendation of starting ART at a CD4count of 350. In its quest to ensure the development of strategies and policies to respond to HIV and AIDS, mitigate the effects of the HIV and AIDS epidemic and promote and coordinate the application of such strategies and policies, the government also introduced home based care programmes in Zimbabwe. Village health workers (NAC) officials visit AIDS victims giving them counselling and support as well as informing them or their relatives of the dates to collect food received from the national government

Information sourced from key informant interviews with some government workers from Masvingo, Zaka district indicates that government distributes very little food to few beneficiaries in home based care programmes. Government's food comes quarterly. Village AIDS action coordinators indicated that the food takes too long and most patients would have died even of malnutrition before receiving the food. Maize and beans as well as cooking oil are distributed through ward/village aids action coordinators. Beneficiaries of the government food programme are very few due to the limited distributions villages receive from the national government. Workshops on HIV prevention and support are also held by NAC officials at schools and townships in rural areas. In-depth interviews with district aids action committee members have revealed that these workshops are not held in liaison with NGOs operating in the same areas with government officials. As a way of empowering orphans the government has introduced the basic education assistance model (BEAM) which is school fees specifically for orphans and the vulnerable. Even though BEAM is a commendable achievement, its execution at the school level lives a lot to be desired. Headmasters are given the prerogative to choose candidates to benefit from the noble government fund and these heads in turn consult the village heads who finally select pupils to be funded. A lot of corruption takes place as families struggle for their children to be included in the programme. Focus group discussions with parents in different districts in Zimbabwe have indicated that village heads have been given goats and chicken so that they include even those children not qualified to benefit from the fund. Several headmasters complained about the late disbursement of the money by government. Government bureaucracy has resulted in increased delays in service delivery. BEAM funds come from the national purse through PAAC to DAAC then the different schools. Evidence has shown that schools may receive this money after two terms hence school headmasters, although they agree that the fund is a noble idea, no longer support it. This is mainly because of the late receipt of the funds which has crippled development activities in their schools.

According to ZNASP (ibid) shortage of foreign currency, high prices of ARVs in the private market, a weakened infrastructure and a critical shortage of trained service providers to treat and follow up patients is weakening government efforts towards the attainment of MDG 6 on HIV and AIDS. The southerntimesafica.com contends that lack of adequate support from the Global fund has hindered an increased response to HIV and AIDS since at present the per 
capita donor spending for HIV/AIDS is about \$4, which means just four United States dollars are allocated per year per person in Zimbabwe compared to as much as $\$ 140$ per person in Uganda according to the southerntimesafrica.com. A huge financial gap exists in terms of funding of the OI/ART programme especially with World Health Organisation of commencing ART at CD4 threshold of 350

\section{The role played by NGOs towards the achievement of MDG 6}

HIV/AIDS development NGOs have been very influential in developing strategies to curtail the spread of HIV/AIDS and help people affected by the virus according to sangonet.org.za. Development NGOs, in particular, have ensured that HIV/AIDS is an integral part of their programmatic focus. Development that is sustainable can only be realised after the curbing of HIV/AIDS. After the declaration of AIDS as a national disaster in 2002, more than 400 NGOs responded by being registered in the Zimbabwe Association for NGOs as prepared to directly work with government in HIV and AIDS programmes. According to pubmed.gov NGOs can be instrumental in providing

- Information on HIV infection and AIDS to the public particularly to special target group populations -- the young, women of reproductive age, and intravenous drug users.

- policy advocacy,

- $\quad$ training for different groups,

- counselling and other assistance to those affected by HIV,

- machines and even screening donated blood,

- and providing care for AIDS patients thus offering a great vehicle for combating the epidemic

According to the World Vision ADP Toolkit for HIV/AIDS Programming (ADP) (2002) World Vision networks for HIV/AIDS response in area development programmes, partners with churches and other Faith Based Organisations on HIV/AIDS Response, care and support for orphans and children as well as home-based care for adults. World Vision also integrates HIV/AIDS responses into existing ADP. In Mutasa ward 17, area one, three, four and nine World Vision has viable support groups, income generating projects which include sewing machines cattle and goat. World Vision is also paying school fees for orphans and the vulnerable in Mutasa district. Key informant interviews with school headmasters have indicated that the NGO has assisted thousands of pupils who might have dropped out of school due to their inability to pay. One of the school heads even proposed the payment of all fees for the vulnerable to be done by World Vision as the payments come on time as compared to fees paid by government. A well balanced diet is a prerequisite for people living with HIV and AIDS (PLWHIV). Gardening projects in Mutasa district have empowered the PLWHIV and orphans as different vegetables are grown both for consumption and marketing. World Vision has 12 area development coordinators who work with VIDCOs and WADCOs. NGOs also distribute food to its beneficiaries. According to NGO workers and World Vision 
food beneficiaries, food comes regularly which therefore implies beneficiaries normally do not encounter shortages in terms of beans, cooking oil and maize meal. CARE international in Masvingo soundly supports PLWHIV and orphans with food.

Focus group discussions with villagers have highlighted that projects implemented by NGOs in districts are not sustainable as they are only viable when NGOs are still operating in their areas. One respondent even pointed to boreholes sunk by an NGO which are no longer functional after the NGO left their district. NGOs have the advantage of adequate human resources due to their high salaries. Government workers in VIDCOs WADCOs are de-motivated by their meagre salaries which they receive after six months. The magnified difference between NGOs and government coordinators' salaries leads to lack of coordination of functions. Government staffs regard NGO staffs as opportunists, donor driven and representing the interests of a particular group rather than the national interests (www.un.org.gvt). Unlike government with diverse functions, NGOs concentrate on HIV/AIDS which leads to their experience in activities to modify sexual behaviour (www.un.org). NGOs are better placed to advance government programmes with respect to HIV/AIDS. They carry out HIV/AIDS situational analysis in their programmes so that their interventions are sensitive to culture and beliefs in their area of operations. NGOs strategically situate themselves in rural areas thereby being able to reach all societies and cultures. Though thorough in their operations, NGOs are limited to a small scale since their costs are very high hence their impacts are felt at grassroots levels/ small scale. In Zimbabwe NGOs have funds at their disposal since they receive funds direct from donors and not through the government due to the mistrust suffered by government after the diversion of a grant in 2008.

Area development coordinators for NGOs are dependable sources of condoms and cotrimoxazole tablets to relieve pain for those in home based care programmes. Coordinators who are permanent residents of areas where they deliver services are equipped with AIDS kits. Interviews with HIV/AIDS victims have shown that coordinators have daily visits to HIV/AIDS victims in their homes. This permits continued assessment of the patients, thus NGOs are deeply involved in complementing government efforts in care and support programmes. Focus group discussions in selected districts have indicated that victims mistake cotrimoxazole for ART. NGOs have also contributed towards the increased number of people aged 15-24 with advanced HIV on ARVs. According to UNGASS $(2008,18)$ the MOHCW 2004 policy 'Plan for the Nationwide Provision of Art' was supported by a number of key players who include donors and NGOs in particular the United Nations Children's Education Fund (UNICEF), United States Government, Clinton Foundation and NAC procured the drug. The Expanded Support Programme supported the Anti-Retro Viral Therapy (ART) in 16 districts (ibid). Programmes for ART included prevention programmes as well as retention scheme programmes.

\section{Nexus between government and NGOs}

Focus group discussions with beneficiaries of both NGOs and government have indicated that there is limited coordination of functions between NGOs themselves and NGOs and 
government. In some areas two NGOs were providing almost the same services to the same people. Christian Care and World Vision are an example. This duplication of function hinders the increased response to HIV/AIDS and derails efforts to attain a single digit HIV prevalence rate by 2015 since efforts are concentrated in some areas whilst no efforts are found in other areas. Repetition of functions among NGOs was witnessed on awareness programmes done in the same areas by different representatives of non-state actors. Competition for donor funds has led to poor coordination amongst NGOs. In-depth interviews with the top managers of NGOs have shown that their organizations are primarily concerned with writing of proposals for funding to their donors and they do not have time to link with other NGOs in terms of their work plans. They focus mainly on the production of quality proposals, which attract funding so that they remain operational, since inability to get funds also implies the closure of the NGO.

According to www.newzimbabwe.com 29 NGOs were de-registered in Masvingo after failing to provide their memorandum of understanding and certificates of registration to the Provincial Administrator (PA) Mr Maluleke. Thus there is no or just limited coordination of functions between NGOs and government. In the PA's direct words(ibid) "we are made to understand that you (meaning NGOs) come to complement the government as partners, but like the bridegroom, you ought to inform the other partner about your activities". NGOs are not even willing to submit their work plans to government hence they are viewed with suspicion by the Zimbabwean government leading to the cancellation of their permits. Zimbabwe has set up the Private Organizations Act under which NGOs operate. Thus the government formulates policies to be implemented by NGOs as implementing agents. HIV/AIDS issues have become political in Zimbabwe and according to Gordenker and Weiss $(1995,547)$ the country may be regarded as a strong state since a weak state cannot set conditions that work as guidelines for NGO operation. NGOs are unwilling to cooperate with government as they foresee no benefit in doing so hence mutual suspicion and hostility envisage the relationship between the two.

The international community's decision to channel funds through NGOs and not government has further crippled the relationship. The government believes that most NGOs have regime change agendas, funded by the British and American government to support Prime Minister Tsvangirai into power. In-depth interviews with some residents in Mutare have indicated that beneficiaries of NGO HIV/AIDS food programmes who wore Zimbabwe African National Union (Patriotic Front) regalia just before the 2008 elections were send back home without receiving their monthly rations. Thus NGOs have to some extend diverted from their core business of being partners in development which supports governor Maluleke's justification for the suspension of the 29 NGOs' activities in Masvingo. Liberalists oppose this view as they argue that NGOs have three functions. Clark, a liberalist portrays three functions of NGOs which are 1) complementing 2) reforming and 3) opposing the state (1991:70). Function 2 and 3 are well documented in Zimbabwe. Government in Zimbabwe is against NGOs performing the third function, whenever they are suspected of being involved in politics of the day, are deregistered as certificates for operation are only granted to NGOs intending to perform function 1. 


\section{Research Implications}

One can conclude that the findings are adding knowledge to the existing body of knowledge on NGOs and their role in HIV/AIDS. Furthermore the findings are important for policy making in general and the MDG discipline that is the health sector in particular.

\section{Conclusion and Recommendations}

HIV/AIDS issues have been politicised both at national and international levels. At the national level the implementation of AIDS policies and programmes has triggered the formulation of policies governing the operations of NGOs for example the Private Organizations Act. The ruling party ZANU PF has noticed that ignoring HIV/AIDS implementation as not politics might lead to its downfall as the party alleges that about 2 5000 NGOs are on regime change agendas. At the international level funding of HIV/AIDS has been sanctioned to the degree that less per head is allocated to HIV/AIDS victims as compared to other African countries like Rwanda and Nigeria. Channelling of HIV/AIDS grants is now through NGOs rather than the government. This has contributed to little or no coordination of efforts between NGOs and government in HIV/AIDS prevention and support. NGOs perceive little benefit in respecting the government as it is not their source of funding. Although NGOs have precarious funding their role in augmenting government efforts in HIV/AIDS cannot be ignored. Some NGOs have pioneered HIV programmes in areas where no programmes have ever been initiated. There is need for NGOs to honour their moral obligations by submitting their work plans to government on time and following all government requirements for operation. This will reduce deregistration. More teachings on the difference between ARVs and cotrimoxazole (a pain killer) are needed in rural areas as the understanding of the difference between the two is confused.

Government of Zimbabwe has become a toothless dog as it only has the power to cancel NGO operations which it cannot replace due to limited funds. It is important for the government to gain trust from the international community so that NGO funds are channelled through it not NGOs. This might help improve coordination of efforts among NGOs themselves and NGOs and government. NGOs due to their participatory approach can operate even in sensitive communities and coordination would lead to the paving of way for government which can operate at a large scale. A more conducive environment for NGO operation needs to be created by government as it should realise the importance of development partners especially during these years of economic hardships in Zimbabwe. There is need for planning as well as resource mobilisation for both government and NGOs for the government to be able to fund all HIV patients in need of ARVs in Zimbabwe due to the World Health recommendation of commencing ART at 350. Zimbabwe has witnessed a sharp decline in HIV prevalence which might continue leading to the attainment of the millennium target of a single digit by 2015. Research has shown that NGOs play a significant role towards the attainment of the target

\section{Areas for further research}

1) The Role Played by Government towards the Achievement of Millennium 
Development Goal of Combating HIV and AIDS

2) The Role Played by NAC in Combating HIV and AIDS

3) Private Sector Policies aimed at alleviating the Impacts of HIV and AIDS at the Workplace

\section{References}

$\underline{\text { Books }}$

Babbie E, (1992) The practice of Social Research, Ally and Bacon, New York.

Bernard D, (1995) Research Methods in Psychology, Longman Press, London

Bryman A, (2003)Social Research Methods, Oxford University Press. Oxford

Makumbe, JM, Participatory Development: The case of Zimbabwe, University of Zimbabwe Publication. Harare, Zimbabwe

Merton R.K, (1956), Theoretical Sociology, New York, Free Press.

Walt, Gill, (1994), Health Policy, san Introduction to Process and Power.

UK: Zed Book Ltd

$\underline{\text { Journals }}$

Aggleton P, et al "Education and HIV/AIDS-30 years on" AIDS Education and Prevention, 123 (6) 495-507 the Guilford Press 2011.

Gordenker, Leon and Weiss, Thomas, G.(1995a).'Pluralising global governance: analythical approaches and dimensions', Third WorldQuarterly, Vol 16, No 3:357-387.

Gordenker, Leon and Weiss, Thomas, G., 1995b. 'NGO participation in the international policy process', Third World Quarterly, Vol 16, No 3:543-555.

Rombo D et al "Family Impact Analysis of Section 6 (Sexual Transmission of the Kenya

HIV and AIDS Prevention and Control" Act Number 14 of 2006 Science + Business Media, LLC 2011

Journal of social and Clinical Psychology Volume 31 No 2 123-150, University of Vermont 2012

\section{$\underline{\text { Websites }}$}

www.aidhttp://www.aid .alliance.org, Accessed on15 October 2011

www.nac.org.zw, Accessed on15 October 2011

www.newzimbabwe.com, Accessed 8 September 2012

www.southertimesafrica.com, Accessed on 15 0ctober 2011 
www.worldvision.org, Accessed 3 September 2012

www.southerntimesafrica.com, Accessed 3 September 2012

www.publicpolicytoolkiy.org, Accessed 5September 2012

www.sangot.org.za, Accessed 8 September 2012

www.un.org, Accessed 3 September 2012

www.english.people.com.cn, Accessed 8 September 2012

\section{Government of Zimbabwe Reports}

Condom Distribution Database and TB Unit, Ministry of Health and Child Welfare (MOHCW), March 2010 Report, Harare, Zimbabwe.

2010 Millennium Development Goals and Status Report Zimbabwe, Harare, Zimbabwe

Ministry of Health and Child Welfare, Zimbabwe HIV estimates 2009, Harare, Zimbabwe

OI/ ART Programme 2008 Annual Report, AIDS and TB Unit MOHCW, Harare, Zimbabwe

Plan for the Nationwide Provision of ART 2009

Review of the National HIV and AIDS Treatment and Care Programme 2004-7, MOHCW 2008, Harare, Zimbabwe

Zimbabwe Human Development Report 2003

Zimbabwe National Strategic Plan 2004

Zimbabwe National Strategic Plan 2008

Zimbabwe National Strategic Plan 2010-15

$\underline{\text { Reports }}$

Fraser Analysis of HIV Epidemic, Response and Models of Transmission 2010Report, Harare, Zimbabwe

Love and Respect Manual for Promoting HIV Prevention Practices, National AIDS Council 2009, Harare, Zimbabwe.

United Nations AIDS 2000 Booklet of best practices, the International Partnership against AIDS in Africa issue 2 UNAIDS Geneva Switzerland.

Southern Africa HIV and AIDS Information Dissemination Service, and HIV Treatment Roadmap for Zimbabwe, December 2009

SADC Expert Think Tank Meeting on HIVs, Maseru, Lesotho.

Prevention in High- Prevalence Countries in Southern Africa Report, Maseru, Lesotho 2006 


\section{Macrothink}

Journal of Public Administration and Governance ISSN 2161-7104 2012, Vol. 2, No. 4

United Nations General Assembly Special Session Report on HIV and AIDS, Zimbabwe country Report (2008 to 2009).

Zimbabwe AIDS Prevention and Support Organization (ZAPSO), Available Services for Psychosocial Support 2001, Harare, Zimbabwe

ZAPSO Annual Report January- December 2001,Harare, Zimbabwe.

ZAPSO, Behavior Change Facilitators Training Manual Report 2010, Harare, Zimbabwe

ZAPSO, Leadership Training Manual 2010, Harare, Zimbabwe

Zimbabwe National HIV and AID Strategic Plan2011-15, Revitalizing our

Commitment to zero infection, zero deaths and Zero discrimination, Harare, Zimbabwe 